\title{
La crisis de la democracia representativa y las tendencias hacia un hiperpresidencialismo, un análisis del caso México
}

The crisis of representative democracy and the tendencies towards a hyper-presidentialism, an analysis of the Mexican case

Autor: Víctor Alejandro Wong Meraz

DOI: https://doi.org/10.19053/16923936.v18.n36.2020.12145

Para citar este artículo:

Wong Meraz, V. A. (2020). La crisis de la democracia representativa y las tendencias hacia un hiperpresidencialismo, un análisis del caso México. Derecho y Realidad, 18 (36),15- 36. 


\title{
LA CRISIS DE LA DEMOCRACIA REPRESENTATIVA Y LAS TENDENCIAS HACIA UN HIPERPRESIDENCIALISMO, UN ANÁLISIS DEL CASO MÉXICO*
}

\author{
The crisis of representative democracy and the tendencies towards a \\ hyper-presidentialism, an analysis of the Mexican case \\ A crise da democracia representativa e as tendências ao hiperpresidencialismo, uma \\ análise do caso do México
}

\author{
Víctor Alejandro Wong Meraz ${ }^{\mathbf{a}}$ \\ awong32@yahoo.com
}

Recepción: 23 de octubre 2020

Aceptación: 10 de noviembre 2020

\section{RESUMEN}

El presente artículo analiza uno de los temas centrales para el constitucionalismo moderno: el control del poder. El cual, con la crisis provocada por el COVID-19, ha puesto en jaque a todas las instituciones democráticas del mundo. Ello ha ocasionado que resurjan las tentaciones de presidentes fuertes, o incluso de llegar a los presidencialismos autoritarios bajo el argumento de poder responder mejor al reto. La metodología que se emplea para la presente investigación será cualitativa, en el sentido de que el análisis resultante es a partir del estudio en diversos textos, de las famosas facultades metaconstitucionales que han repercutido en la realidad constitucional. Igualmente, se analizarán los resultados de 2018, teniendo en cuenta que podría detonar las facultades metaconstitucionales del presidente mexicano. Como resultado de la investigación se acredita la importancia del estudio del debate del constitucional suscitado en la República de Weimar, en la época Entre Guerras. El cual, es considerado el de mayor rigor científico y que más ha aportado a las ciencias jurídicas. Allí podemos caer en el positivismo jurídico de Kelsen, decisionismo de Schmitt, integracionismo de Smend, o la metodología de las ciencias constitucionales de Heller.

\section{PALABRAS CLAVES}

Constitucionalismo; democracia representativa; hiperpresidencialismo; crisis institucional; México.

\section{ABSTRACT}

This article analyzes one of the central issues for modern constitutionalism: the

\footnotetext{
* Artículo de reflexión. Agradezco los comentarios realizados por Christian Yair Aldrete y Fernando Leopoldo González para la elaboración de este trabajo.

a. Doctor en Derecho Constitucional por la Universidad Complutense de Madrid, miembro del Sistema Nacional de Investigadores Nivel I. Profesor Investigador de la Universidad Autónoma del Estado de México.
} 
control of power. With the crisis provoked by COVID-19, it has put all the world's democratic institutions in check. This has caused the temptation of strong presidents to resurface, or even to reach out to authoritarian presidentialisms under the argument of being able to respond better to the challenge. The methodology used for this research will be qualitative, in the sense that the resulting analysis is based on the study in various texts of the famous metaconstitutional faculties that have had an impact on constitutional reality. Likewise, the results of 2018 will be analyzed, considering that it could detonate the meta-constitutional faculties of the Mexican president. As a result of the research, the importance of the study of the constitutional debate in the Weimar Republic, during the Between Wars period, is proven. It is considered the most rigorous and has contributed the most to juridical sciences. There we can fall into the juridical positivism of Kelsen, the decisionism of Schmitt, the integrationist of Smend, or the methodology of the constitutional sciences of Heller.

\section{KEYWORDS}

COVID-19; Presidentialism; Constitution; Mexico; pandemic; Latin America.

\section{RESUMO}

Este artigo analisa um dos temas centrais do constitucionalismo moderno: o controle do poder. Que, com a crise provocada pela COVID-19, colocou em xeque todas as instituições democráticas do mundo. Isso fez que as tentações de presidentes fortes reaparecessem, ou mesmo alcançar o presidencialismo autoritário, sob o argumento de serem capazes de responder melhor ao desafio. A metodologia utilizada para esta pesquisa será qualitativa, no sentido de que a análise resultante se baseia no estudo em diversos textos dos famosos poderes metaconstitucionais que tiveram impacto na realidade constitucional. Da mesma forma, serão analisados os resultados de 2018, levando-se em conta que pode detonar os poderes metaconstitucionais do presidente mexicano. Como resultado da pesquisa, credita-se a importância do estudo do debate constitucional surgido na República de Weimar, na era Entre Guerras. Que é considerada a que tem maior rigor científico e que mais tem contribuído para as ciências jurídicas. Aí podemos cair no positivismo jurídico de Kelsen, no decisionismo de Schmitt, no integracionismo de Smend ou na metodologia de Heller das ciências constitucionais.

\section{PALAVRAS-CHAVE:}

Constitucionalismo; hiperpresidencialismo; democracia representativa; crise institucional; México.

\section{SUMARIO}

Introducción.

1. Democracia: sinónimo de Derechos Humanos y equilibrio de poder.

2. La Democracia y su desarrollo. 3. Democracia Representativa y Partidos Políticos.

4. Percepción ciudadana de la Democracia. 5. Las facultades metaconstitucionales y el presidencialismo mexicano.

6. La cuarta transformación y la remasterización del presidencialismo mexicano.

7. El debate teórico de Weimar y el preludio de la crisis constitucional actual.

8. Normalidad vs Normatividad: la tensión actual.

Consideraciones Finales.

Referencias bibliográficas.

\section{INTRODUCCIÓN}

La realidad ha cambiado de forma tan acelerada que el humano tardará en acostumbrarse a la nueva normalidad. La erupción del COVID-19 ${ }^{1}$, ha provocado que todas nuestras ideas, o formas de llevar a cabo las cosas, se replanteen y nuestras instituciones jurídicas, políticas, económicas y sociales no serán la excepción. Se ha visto

1. De acuerdo con el conteo de la Universidad John Hopkins, al momento de redactar estas líneas, existían más de 42,000,000 de casos confirmados y más de 1,140,000 de defunciones. https://coronavirus.jhu.edu/ map.html 
cómo distintas latitudes enfrentaron la situación, así como escucharon distintas voces $o$ análisis que, en cierta medida, afirman cómo los países con regímenes autoritarios han logrado mejores resultados. Ello en relación con los obtenidos por los Estados democráticos en el combate a dicha enfermedad, la cual ha azotado a todo el mundo ${ }^{2}$. Por lo anterior, se ha pronunciado la posibilidad de que la democracia sufra grandes retoques. Cuando se menciona la democracia se refiere a la democracia constitucional, que abarca el respeto a los derechos humanos o fundamentales $\mathrm{y}$ al equilibrio de poder. Asimismo, la posibilidad de una renovación de toda una clase política, ya que de acuerdo con el resultado frente a la pandemia que cada estado diera, se convertirá en el termómetro o forma de medir a quienes ostentan el poder. Por tal motivo, la democracia se encuentra en momento de inflexión, ya que podemos ubicar, en cierta medida, las crisis constitucionales en las que estamos, a la que se suscitó Weimar en la época Entre Guerras. Las tensiones se asemejan, y de acuerdo con los distintos planteamientos teóricos podemos encontrar soluciones o inclusive retroceder en las conquistas ya logradas. Tales respuestas pueden inclinarse por el positivismo de Kelsen, decisionismo de Schmitt, integracionismo de Smend, o el análisis de metodológico de las ciencias constitucionales de Heller (RUIPÉREZ, 2010, p. 705). No obstante, la situación actual pudiera ser más crítica, ya que no solamente se juega con la visión de la democracia constitucional de una región o parte del

2. Un ejemplo de esto es el caso de China, país donde broto la pandemia a finales del año pasado, sin embargo, hoy es el país que de una forma u otra está regresando a la normalidad. Este país asiático, enfrentó la pandemia con restricciones bastantes severas a distintos derechos, como pueden ser la libertad de tránsito y el seguimiento de las personas con el Big Data; logro aislar a toda la comunidad de Wuhan, con más de 20 millones de habitantes, lugar donde fue el inicio de la crisis sanitaria. En este momento, en occidente se era muy crítico con las medidas adoptadas por China, ya que se consideró que estaban vulnerando los derechos humanos y que eso no sería la forma de enfrentar la pandemia. Sin embargo, en estos momentos, los países de occidente, Europa y América han sido los más devastados por el Coronavirus, ya que en estas dos regiones se encuentran más del $75 \%$ de las muertes totales, y el caso más alarmante es Estado Unidos de América con más de 8,440,000 de infectados y más de 223,000 defunciones. mundo, como lo fue en Alemania de los años 30s. Hoy, todo el mundo se enfrenta a una crisis económica, política, social y sanitaria, con lo cual, la tendencia a plantear regímenes autoritarios, pero "eficientes" se vuelve cada día más latente. Por tal motivo, resulta imperativo entender las líneas del propio Platón, cuando realiza su análisis de las distintas formas de Estado, y afirma que: en el momento que fracasan las democracias se instauran las tiranías (PLATÓN, 2006, p. 90).

En tal sentido se inclina la presente investigación, ya que, frente a la crisis mundial provocada por el COVID-19 en todos los ámbitos, se vislumbran distintos escenarios. Lamentablemente, ninguno de ellos resulta alentador para la democracia constitucional, ya que, por un lado, puede haber la renovación de toda una clase política, o, por el contrario, pueden consolidarse los regímenes autoritarios como solución a los problemas, y México no será la excepción al momento de enfrentarlos.

\section{DEMOCRACIA: SINÓNIMO DE DERECHOS HUMANOS Y EQUILIBRIO DE PODER}

Una de las preocupaciones del constitucionalismo moderno es la de perfeccionar el papel de la Constitución como instrumento de control, por tal motivo, el estudio de los distintos medios o mecanismos son el objetivo de limitar y controlar el poder. En ese sentido, la división de poderes es el fundamento de la sujeción jurídica del Estado. La cual, se basa en la validez jurídica de los derechos humanos y ellos a la vez son el soporte de la democracia.

Para algunos, los derechos humanos suponen una constante histórica cuyas raíces se remontan a las instituciones y el pensamiento del mundo clásico. Otros, por el contrario, sostienen que la idea de los derechos humanos nace con la afirmación cristiana de la dignidad del hombre en cuanto persona. Frente a estos últimos, a su vez hay quienes afirma que el cristianismo no supuso un mensaje de libertad, sino más bien de una aceptación conformista a 
la esclavitud humana. Sin embargo, la más frecuente es considerar que la primera aparición de la idea de derechos humanos tiene lugar durante la lucha de los pueblos contra el régimen feudal y la formación de las relaciones burguesas (PÉREZ LUÑO, 2001, p. 123).

No obstante, en los procesos revolucionarios burgueses del siglo $\mathrm{XVIII}^{3}$ se siguieron dos líneas de pensamiento perfectamente diferenciables. La primera se encuentra una formulación desde el punto de vista pactista, o del iusnaturalismo contractualista, en los cuales podemos destacar a Hobbes, Locke y Rousseau. La segunda postura, preocupada no tanto en justificar el poder sino como propiciar su limitación, se sitúa en la subordinación del gobernante a la ley, la cual gira alrededor de la institucionalización del poder, entre los que se destaca Montesquieu y Constant.

Ambas corrientes responden a objetivos diversos y cumplen finalidades distintas. Sin embargo, subyace una contraposición indudable de la que es necesario dejar constancia, pues al anticipar la historia de la problemática, a nivel teórico, se posibilita la comprensión del significado, fundamento y alcance de la reforma constitucional (VEGA GARCÍA, 2000, p. 89). Con las revoluciones políticas liberales la Constitución, como Norma Fundamental del Estado, queda consagrada bajo la premisa de creación exacta del pacto originador de las nuevas relaciones de poder. Fundadas en la garantía de los derechos naturales del individuo miembro de la comunidad política, siendo el ejercicio de su libertad civil, política y económica el verdadero factor determinante del nuevo orden político.

El derecho natural racionalista y su planteamiento de los derechos naturales, las categorías filosóficas de la Ilustración y finalmente del liberalismo político, son hitos del pensamiento occidental moderno. Las

3. Estos dos movimientos fueron la Revolución francesa y que tiene como resultado la Declaración Universal de los Derechos del Hombre y del Ciudadano del 26 de agosto de 1789, y la Independencia de los Estados Unidos de América en el año 1787. cuales, darán nueva medida a la soberanía política, procedente de la transformación de su concepto clásico (WONG MERAZ, 2010, p. 67). Por su parte, en la teoría de la institucionalización del poder se encuentra el marco de la democracia representativa, la diferenciación entre gobernantes y gobernados. La cual, no ofrecerá mayores dificultades para concebir la Constitución como ley suprema, a través de la cual se pretende controlar y limitar, en nombre de la voluntad soberana del pueblo, la voluntad no soberana del gobernante. Cuando se considera que el gobernante no es soberano, sus competencias y atribuciones se encuentran configuradas por la ley. Lo que equivale a indicar que la Ley Suprema es un mecanismo de control del poder, en la medida en que es, a su vez, el dispositivo de organización de las competencias y atribuciones de los diferentes órganos estatales.

Montesquieu es quien mejor logró definir la tesis del principio democrático y la teoría limitadora del poder en su obra Del Espíritu de las Leyes. Es allí donde se encuentran los precedentes y fundamentos más sólidos sobre los que se elaboró, luego, la concepción de la Constitución como ley suprema. Dicho trabajo se constituyó, en el siglo XVIII, como la versión más humana y completa. La Declaración de los Derechos del Hombre de 1789 (PECES-BARBA MARTÍNEZ, 1993, p. 234.), en su artículo 16, establece: "Toute société dans laquelle la garantie des droits nést pas asureé ni la séparation de pouvoirs détermiée, ná pas de Constitution» ${ }^{4}$. Dicho precepto contiene el axioma más importante de la ciencia política, el de la separación de poderes (JELLINEK, 1981, p. 267.), en virtud de que dicha máxima ha dejado una marca profunda en los espíritus de los constituyentes, que lo han plasmado en las constituciones.

La constitucionalización del poder, su limitación y control responden, en definitiva,

4. Declaración de los derechos del hombre y del ciudadano del 26 de agosto de 1789. Artículo 16: "Toda sociedad en la cual no esté establecida la garantía de los derechos del hombre, ni determinada la separación de los poderes, carece de Constitución. 
a la legitimación y garantía de la libertad en el marco del Estado moderno. Es decir, aquella comunidad de individuos dotada de una particular trascendencia, ordenada mediante una determinada legalidad e institucionalidad (MONTESQUIEU, 2000, p. 367). Heller afirma que la doctrina de la división de poderes de Montesquieu no es sino un procedimiento técnico para transformar la voluntad general, portadora y creadora de los valores, en una ley cuya imperatividad no admita perturbaciones. En la importancia de esa separación de poderes se encuentra la respuesta del constitucionalismo moderno contra el peligro recurrente del despotismo.

La división de poderes, la idea de democracia, la doctrina de la corporación y la teoría de los órganos del Estado, tienen como misión hacernos concebir la voluntad del titular de la soberanía como una voluntad limpia de toda subjetividad. Ello quiere decir que la voluntad del Estado debe ser concebida como una norma autónoma y objetiva, en la que no se desempeñe función alguna el árbitro individual (HELLER, 1995, p. 123). Si bien es cierto, Montesquieu habla de una división de poderes, sin embargo, lo que en realidad está manifestando es una coordinación de los mismos. Ya que, en la medida que se accione uno, los otros van a servir de frenos y contrapesos. En tal sentido, hemos mencionado más que una separación de poderes es un equilibrio de poder, el cual se encuentra cimentado sobre una mesa de tres patas. En donde, si se distribuye el poder correctamente, puede soportar cualquier caso. No obstante, en el momento en que se carga más sobre una de sus patas o columnas, el Estado constitucional se derrumba como un castillo de naipes.

\section{LA DEMOCRACIA Y SU DESARROLLO}

Hoy en día la discusión sobre la democracia como sistema político ha dejado de ser un tema central. El proceso de universalización de la democracia se ha ido acelerando desde la década de los noventa, del siglo pasado, hasta nuestros días. Sin embargo, es importante recordar que a finales del siglo XVIII sólo había tres estados democráticos: Suiza, Estados Unidos y Francia. La primera etapa de democratización comienza en 1828 y se extiende hasta 1926. En 1900 había 13 estados democráticos y para 1919 ya eran 27. En la década de los treinta la democracia sufrió un gran retroceso y la cifra de países democráticos se redujo a sólo 14 . La segunda etapa se inicia en 1945 con la democratización de Alemania, Italia y Japón, la cual finaliza en 1962 cuando los sistemas políticos democráticos llegan a ser 36 países. La tercera etapa de democratización comienza a mediados de los años setenta y el rasgo más distintivo es que alcanza el mundo comunista. Pese al enorme avance, en 1991 la mayoría de la población mundial, el 56\%, vivía en países carentes del reconocimiento de libertades (TARNAWSKI GESLOWSKA, 1994, p. 98). Sin embargo, ahora, en la segunda década del segundo milenio, la gran mayoría de los estados se puede afirmar que son democráticos, unos más que otros, pero al fin democráticos.

Por tal motivo, la discusión ya no se centra en el sistema democrático, sino en qué tipo de democracia se busca: la democracia participativa o la representativa. En el primer caso, el pueblo no se limita a expresar la opción electoral, sino que también adopta algunas decisiones gubernamentales que indican diversamente la orientación de los órganos representativos (VERGOTTINI, 2004 , p. 487). Por otro lado, tenemos que, en la democracia representativa, el pueblo se entiende como un ente real, de personas con voluntad propia y singular. Sin embargo, aquellas se encuentran con necesidades de intermediación representativa, pero siempre a partir de voluntades singulares e iguales, para fabricar, mediante el derecho, una verdadera voluntad política coherente y operativa (FERNÁNDEZ MIRANDA CAMPOAMOR, 2003, p. 98). El pueblo no existe como realidad con capacidad de decidir, sino que decide un sector del pueblo (WONG MERAZ, 2014, p. 222).

Nuestra región se encuentra sumida en una crisis democrática, que se entiende al asumir que, lamentablemente, no se han podido solucionar los problemas 
que aquejan a la mayoría de la población. Como lo veremos más adelante, existe una gran porción de la gente que no cree que la democracia sea el mejor mecanismo para guiar una sociedad. Algunas de las soluciones planteadas para acercar al ciudadano a los asuntos públicos son a través de los partidos políticos, donde pueda tomar una función más activa en la toma de decisiones. El objetivo es hacerlo copartícipe y corresponsable en los designios del Estado.

\section{DEMOCRACIA \\ REPRESENTATIVA Y PARTIDOS POLÍTICOS}

La democracia representativa descansa fundamentalmente en el concepto de la representación política, en otras palabras, no podemos hablar de democracia sino es a través de la democracia representativa. Sobre los fundamentos planteados por Montesquieu, Sieyès establece la distinción entre democracia y gobierno representativo. El teórico de la Revolución francesa afirma que la utilidad común se deben designar representantes más capaces o preparados que las personas comunes, ya que los primeros conocerán mejor el interés general y así podrán interpretar la voluntad general (SIEYES, 1989 p. 97), es decir, los diputados de la nación. En este sentido, Carré de Malberg establece que lo que se encuentra en el régimen representativo no es un sistema de representación personal y de la voluntad nacional, sino precisamente un sistema de organización de la voluntad y de la persona nacional (CARRÉ DE MALBERG, 1988, p. 667).

De acuerdo con líneas anteriores, la teoría democrática de la representación, cuando se plantea el vocablo pueblo, se entiende como un ente real de personas con voluntad propia y singular. No obstante, aquellas se encuentran con necesidades de intermediación representativa (HAMILTON, MADISON Y JAY, 1974, p. 187), pero siempre a partir de las voluntades singulares e iguales. Para crear, mediante el derecho, una real voluntad política coherente y operativa. Por tal motivo, el pueblo no existe como realidad con capacidad de decidir, sino que decide como pueblo sectorizado.

La democracia constitucional se sustenta fundamentalmente en el concepto de Representación política (PITKIN, 1985, p. 89), en la cual el legislador representa a la Nación entera y no sólo a una porción. El mandato que se les hace a los representantes es de carácter general, es decir, no se encuentra limitado a cuestiones concretas. Se trata de un mandato libre, puesto que el representante opina lo que le parece conveniente, no estando sujeto a ninguna instrucción ni mandato imperativo alguno. No es responsable ante nadie, ya que sus electores no lo pueden revocar. El legislador no sólo va a velar por los intereses de las personas que lo eligieron, del distrito que representan o de su partido político, sino de la Nación entera (BURKE, 1996, p. 165).

En esta línea discursiva, no podemos plantear la discusión de la democracia representativa sino es a través de los partidos políticos, ya que son una respuesta a la masificación de las decisiones ciudadanas, es la forma en que la democracia funciona y se mantiene (DUVERGER, 1970, p. 245). Son los canales de ascenso para las necesidades sociales y que las propuestas entren a la competencia ante el árbitro que es la ciudadanía (DI TELLA, 1988, p. 98). Sin embargo, el mandato imperativo, que se encuentra prohibido en la mayoría de las constituciones modernas, se ha convertido en una realidad indiscutible de la actual democracia representativa, en la que los representantes se ven obligados a seguir los dictados de los partidos políticos sin poder actuar de una forma espontánea y libre (VEGA GARCÍA, 2000, p.108). Es lo que Michels definió como la Ley de Hierro o de la oligarquía dentro de los partidos políticos (MICHELS, 2003, p. 123).

Para Loewenstein desde la aparición de los partidos políticos el mandato imperativo se ha convertido en un fenómeno común, ya que el representante se encuentra sujeto a una disciplina más o menos estricta, que lo obliga a votar según las decisiones de liderazgo del partido político al que pertenece. De esta manera, el mandato imperativo prohibido 
en la Constitución en realidad se produce en la práctica (LOEWENSTEIN, 1986, p. 356). En tal sentido, Bobbio afirma que la clara diferencia entre Constitución formal y real, desde el punto de vista de la superioridad del particularismo sobre el principio de unidad orgánica, es la práctica inoperante de la prohibición del mandato imperativo. Ya que, en la actualidad, no es la forma en que se toman las decisiones en los Parlamentos, donde los legisladores están obligados a defender intereses nacionales contra intereses parciales, sino que obedecen a grupos de presión que, en cierto sentido, representan intereses más particulares que los de propios partidos (BOBBIO, 1992, p. 78).

También hay que agregar que en toda democracia representativa los actores políticos buscan el consenso, y es precisamente en ese momento en que la negociación política cobra una gran fuerza, ocasionando un juego de prestación y contraprestación entre los partidos políticos, ya que estos van a buscar lo que más convenga a su partido y, en la gran mayoría de las veces, no es lo que más beneficia a la Nación.

\section{PERCEPCIÓN CIUDADANA DE LA DEMOCRACIA}

En líneas anteriores se han analizado, desde el punto de vista teórico y jurídico, los elementos de la democracia, en este sentido, un estudio sobre el sistema de libertades sería parcial al no conocer la opinión a quienes va dirigida, que son los propios individuos.

Después de la Segunda Guerra Mundial, en Europa., se logró una mayor estabilidad democrática, aunado a un desarrollo económico impresionante. Sin embargo, en América Latina no fue así, ya que ha sufrido varios fracasos democráticos, debido a golpes de Estado, siendo los últimos el de Bolivia $^{5}$ de 2019 y el de Honduras ${ }^{6}$ en el

5. El presidente en funciones Evo Morales se vio obligado a renunciar.

6. El presidente Manuel Celaya sufrió un golpe de estado, derivado de sus pretensiones de llevar a cabo
2009. En la zona se han producido gobiernos autocráticos, militares y dictatoriales, aunados a graves problemas sociales $\mathrm{y}$ económicos, lo que ha provocado que aproximadamente el $43 \%$ de los habitantes de la región viven en la pobreza. Es el lugar con mayores niveles de desigualdad social en todo el mundo, la concentración de la riqueza es indignante y los rezagos en los sistemas de salud, educación y vivienda son inmensos (CARPIZO, 2009, p. 165).

Para continuar, seguiremos el planteamiento realizado por Carpizo en sus escritos sobre el arraigo de la democracia en América Latina, con un análisis del último reporte del Latino barómetro. Dicho estudio arroja que, en relación con el apoyo de la democracia, baja el promedio en la región de un $61 \%$ a un $58 \%$, después de cuatro años que se había sostenido en aumento. El impacto negativo en el apoyo a la democracia proviene tanto del plano económico como del político. Lo más destacado es la baja en el promedio de la región entre el año 2010 y 2011, ya que catorce países analizados sufren una disminución de su percepción de la democracia. En Guatemala y Honduras bajan 10 puntos porcentuales, Brasil y México nueve, y Nicaragua ocho, Costa Rica y Venezuela siete, el resto de los países bajan entre cinco o más puntos porcentuales. Por ejemplo, en México se sufre el retroceso por la ola de violencia, que a la vez ha tenido una disminución del crecimiento del $-1.4 \%$ entre 2010 y 2011. La caída en la percepción de progreso es de $2 \%$ y el índice de confianza de los consumidores es del $44 \%$.

Los resultados que arroja sobre las actitudes hacia los gobiernos militares disminuyeron, en 2011, al 63\% en relación, a un $66 \%$ del 2010 . No obstante, Guatemala es el país de la región que menos rechaza a

una consulta para poder modificar la constitución y poder permitir la reelección, tema prohibido por texto constitucional. La Corte y el parlamento de Honduras advirtieron al presidente de que estaría violando la constitución en su pretensión de reelegirse, así que llevaron a cabo un golpe de Estado, provocando que el presidente saliera de país. Lo irónico de esto, es quienes perpetuaron el golpe de estado, argumentando la defensa de la constitución, al corto tiempo, llevaron a cabo una reforma constitucional, eliminando esa cláusula pétrea que era el periodo constitucional. 
los gobiernos militares, donde el $60 \%$ no repudia un régimen militar. Otros países con índices alarmantes son Paraguay 52\%, México 53\%, y Perú 54\%, donde la población se encuentra dividida respecto al rechazo. Los regímenes autoritarios o totalitarios es donde la policía se eleva hasta la cumbre del poder con la pretensión de consolidarse a través de la dominación de amplios grupos de personas al margen de cualquier delito cometido por los individuos (ARENDT, 2017, p. 399).

Tal y como se afirma, los gobernantes de la región más y más utilizan la democracia participativa y, en específico, el instrumento del referéndum constitucional, con el objeto de manipular la voluntad del pueblo, y así legitimar sus arbitrariedades. Ello resulta contradictorio cuando pensamos que la utilización de los mecanismos de la democracia participativa sirve para atenuar a los sistemas presidenciales y como freno a los sistemas representativos. Sin embargo, la historia nos demuestra lo contrario, ya que, a través de dichos módulos, se ha logrado acentuar la versión más autoritaria de los mismos, ya que han servido para legitimar las decisiones ya tomadas, y como justificación de las mismas, bajo el respaldo de un apoyo por parte del pueblo. Eso provoca que los castillos democráticos que hemos construido en la playa se desvanezcan a la primera acrecentada de oleaje que tengamos.

\section{LAS FACULTADES METACONSTITUCIONALES Y EL PRESIDENCIALISMO MEXICANO}

El exceso del presidencialismo que ha ocasionado el predominio del Poder Ejecutivo sobre el Poder Legislativo no es exclusivo de México. Carpizo (2004, p. 46) señala que también en América Latina, en los sistemas presidenciales, ha ocurrido tal hegemonía cuyos rasgos relevantes son la existencia de un gobierno autoritario, la concentración de las atribuciones legislativas y ejecutivas en el presidente, la subordinación de los poderes legislativos y judiciales al ejecutivo. Lo cual, para algunos se considera como el neopresidencialismo.
Sin embargo, las atribuciones del presidente en México no pueden solamente explicadas desde la perspectiva jurídica, sino que se tienen que analizar en conjunto desde el enfoque político. Ello se puede entender, ya que al haber existido durante más de 70 años un partido político dominante en el poder, PRI (Partido Revolucionario ${ }^{7}$ Institucional) ${ }^{8}$, se provocó un afianzamiento de la figura del presidente. Algunos han planteado que durante aquella época se tenía un partido único. Sin embargo, ello no es cierto, ya que en nuestro país siempre han existido una pluralidad de partidos, desde sus inicios como república en $1824^{9}$, y hasta nuestros días. Después de la revolución mexicana de 1910, la cual originó nuestro actual Texto Constitucional, se ocasionó la cimentación de un partido hegemónico: el PRI. De acuerdo con Sartori, son los partidos políticos los que tienen todas las condiciones

7. Consideramos que es un contrasentido la denominación de Revolucionario Institucional, ya que la figura menos institucional es propiamente la revolución.

8. Este partido tiene su antecedente en 1929, año en el cual fue fundado por el presidente Plutarco Elías Calles con el nombre de Partido Nacional Revolucionario. En el año de 1938 se cambia el nombre a Partido de la Revolución Mexicana, y en 1946 se establece el nombre actual, Partido Revolucionario Institucional. Para algunos la clave del PRI se encuentra en la posibilidad de que todas las corrientes tenían cabida dentro partido, las ideologías o grupos representativos del país. Se podría tomar la analogía del péndulo de un reloj, ya que este va de izquierda y derecha, y era precisamente ese el funcionamiento del PRI en cuestión ideológica, ya que esa visión la imponía el presidente en turno. Es importante resaltar esto, ya que se menciona que la primera crisis interna sucede cuando esta ideología se queda en la derecha, y como la clave era se retornó a la izquierda, cuando esto no sucede, un gran grupo de militantes deciden abandonar las filas de este partido, ya que consideran que se han traicionado los ideales revolucionarios, los cuáles fueron motor de la política nacional. Entre los disidentes, podemos destacar a Cuauhtémoc Cárdenas, Porfirio Muñoz Ledo, Ifigenia Martínez y Andrés Manuel López Obrador, quienes a la postre van a formar el Partido de la Revolución Democrática.

9. Para la primera elección en México de 1828, participaron dos candidatos, los cuáles fueron impulsados por las logias masónicas; por un lado, la Yorkina que postuló al General Vicente Guerrero y por el otro lado, tenemos a la escocesa con el General Gómez Pedraza. Lo interesante de esto, es que, desde el primer procesado electoral llevado a cabo en el México Independiente, se cuestionó el propio resultado, y esto ha sido la constante durante gran parte historia como nación. Además, hay resaltar, que estas logias masónicas son el primer antecedente de los partidos políticos, de Yorkina-escoces a liberal-conservador y de federalistascentralistas. 
para ganar las elecciones (SARTORI, 2005, p. 82).

El hiperpresidencialismo ${ }^{10}$ se vio reflejado en todas las esferas, y la Constitución no podía ser la excepción. La Carta Magna se vio sujeta a tantas modificaciones como las veces que considerara necesario el presidente de la república. En tal sentido, durante todo el periodo del partido hegemónico, el cual contaba con amplias mayorías, tanto en el Congreso de la Unión como en el de las Legislaturas de las Entidades Federativas, se originó en la práctica un procedimiento de reforma flexible, a pesar de estar regulado en la Constitución como rígido. Ello se debió, principalmente, a las aplastantes mayorías parlamentarias con que dicho partido contó y logró superar cualquier requisito constitucional, por más rígido que pareciera.

La Carta Magna mexicana se ha visto tan flexible que ha sido objeto de más de 800 reformas. Lo característico fue que las reformas aumentaron simultáneamente con la inestabilidad en la cual entró el sistema constitucional en la década de los años 70s. En dicha etapa, los presidentes de la república lograron aumentar al doble el número de reformas que sus antecesores habían propuesto y logrado. El hecho de que en una Constitución predomine la rigidez, como es el caso mexicano, no implica que sea su única y definitiva característica, ya que en la práctica se puede modificar las veces que se crea necesario, por parte de los jefes del Ejecutivo.

Uno de los artículos que se ha sometido a más revisiones es el 73, en el cual se establecen las Facultades del Congreso de la Unión. Dicho precepto es el que más reformas ha sufrido en la historia de la actual Ley Fundamental, en virtud de que cuenta con más 60 reformas en total. La mencionada pauta constitucional forma parte de la Sección III del capítulo II relativo al Poder

10. Consideramos Hiperpresidencialismo cuando existe un desequilibrio de poder a favor del titular del ejecutivo, y esto puede devenir desde la parte orgánica de la constitución, o lo que es más peligroso, cuando provienen de la realidad constitucional, que se conocen como las facultades metaconstitucionales.
Legislativo. Dicha sección III se intitula "de las facultades del Congreso de la Unión". En ese articulado se describen las facultades que ejercen ambas Cámaras, la de diputados y senadores en forma conjunta y separada. En el 74, las que son de la Cámara de Diputados, y en el 76, las exclusivas de la Cámara de Senadores.

El artículo 73 es uno de los más importantes instrumentos jurídicos del federalismo mexicano. Dado que el sistema federal implica dos planos simultáneos de gobierno, el general o nacional que abarca toda la República, y el particular de cada uno de las Entidades Federativas, es necesario para su funcionamiento precisar el ámbito de competencia de cada uno de estos planos y distinguir las facultades de los órganos federales y de los Poderes Locales. Para ello, nuestro sistema constitucional se complementa con el artículo 124 que establece: "las facultades que no están expresamente concedidas por esta Constitución a los funcionarios federales se entienden reservados a los Estados". Así, se constituye un sistema de facultades explícitas, de tal modo que las facultades federales han de estar necesariamente específicas en el texto de la Constitución y, en consecuencia, todas las demás pertenecen al ámbito de las Entidades Federativas.

El Constituyente de Querétaro aprobó el artículo 73, integrado por 31 fracciones. De las cuales 15 permanecen tal cual como aparecen en el texto constitucional de 1917, y 16 han sido modificadas o adicionadas, en una o varias ocasiones. Como resultado el sistema de equilibrio de poder y el sistema federal en México, se ha ido desvirtuando, provocando un centralismo que gira alrededor de la figura del presidente de la república. Ya que, además de ser el Jefe de Gobierno y de Estado, era en su momento, también jefe del partido en el poder $y$, como asentó, ese partido contó con mayorías aplastantes en el Congreso. Los legisladores debían, en gran parte, su candidatura y su futuro o carrera política a la decisión presidencial. 
Para Carpizo el presidente mexicano tenía múltiples facultades que provenían de distintas fuentes, como la Constitución, las leyes ordinarias y el sistema político. De las anteriores fuentes, hay que entender que el primer mandatario del país obtuvo la gran fuerza o poder de la última de ellas, o sea, del sistema político mexicano, a lo que este autor ha denominado las "facultades metaconstitucionales". Ellas son atribuciones con las que contaba el presidente situadas más allá del marco constitucional, como eran la designación de su sucesor, el nombramiento de los gobernadores, los senadores, de la mayoría de los diputados, de los principales presidentes municipales, entre otros. Por ser del PRI, un partido predominante $y$ semioficial integrado por sectores, se le concedía al presidente control sobre las principales organizaciones (CARPIZO, 2004, p. 94).

Entre las facultades que provienen de leyes ordinarias se puede mencionar: su intervención en los organismos descentralizados y empresas de participación estatal y su intromisión en los medios de comunicación masiva. Debe tenerse en cuenta que existen facultades que se ubican tanto en la Constitución como en leyes secundarias. Por ejemplo, es muy importante la facultad del presidente para designar a sus más cercanos colaboradores, atribución cuyo fundamento es el artículo 89 constitucional. Sin embargo, leyes ordinarias también le conceden facultades de nombramiento, tal y como acontece con diversas clases, así como con funcionarios de organismos descentralizados y empresas de participación estatal.

En relación a la conformación de las ternas que presenta el presidente al senado para la designación de ministros de la Suprema Corte de Justicia de la Nación, es de todos sabido que será nombrada la persona que titular del ejecutivo pretende que ocupe el cargo. Ya que los Senadores se verán sometidos a la voluntad del líder. En materia económica, sus facultades derivan también tanto de la constitución como de la ley ordinaria. Como ejemplos de facultades que provienen del sistema político podemos mencionar: su papel como jefe del PRI, la designación de su sucesor y de los gobernadores, organizaciones obreras, campesinas, profesionales y de diversa índole, las cuales eran las organizaciones más fuertes de México.

Hay que resaltar que en el momento de mayor fuerza del presidente de la república también empezaba su debilidad. En el instante que el presidente nombraba a su sucesor, iniciaba su debilitamiento, en palabras clásicas de la historia: "muera el Rey, viva el Rey". Sin embargo, hay que apuntar que nuestra Ley Fundamental, si bien estructuró un Poder Ejecutivo fuerte, de ninguna manera lo deseó ilimitado, ni por encima de la ley. Ya que, el presidente es responsable de sus actos, además que existen, en el propio ordenamiento, facultades que pueden ser usadas como controles entre los poderes legislativo y ejecutivo, con la intención de obtener un equilibrio de poderes. Dentro de los controles políticos encontramos los siguientes:

a) El poder de la bolsa,

b) La ratificación de determinados actos,

c) El juicio político de responsabilidad,

d) Las sesiones extraordinarias, y

e) Las facultades implícitas.

Sin embargo, tales frenos y contrapesos, antes de la alternancia y cambio de la realidad política en México, no existían. Ya que, el presidente logró subordinar a los miembros del Congreso de la Unión, por las siguientes razones:

a) La gran mayoría de los legisladores pertenecían al PRI, del cual el Primer mandatario, era el jefe, y a través de la disciplina de partido, aprobaban las medidas que el ejecutivo deseaba;

b) Si se revelaban, lo más probable era que terminara su carrera política, ya que el titular del ejecutivo era quien nombraba los principales cargos y puestos de la Administración Pública, en el sector paraestatal, en los de elección popular y en el Poder Judicial; 
c) Por agradecimiento, ya que debían su puesto a la designación del presidente;

d) Además del sueldo, existían otras prestaciones económicas que dependían del líder, y con esto crecía el control político;

e) Aceptación de que el Poder Legislativo seguía los dictados del presidente, lo cual resultaba una actitud más cómoda y de menor esfuerzo.

Para entender la realidad política mexicana debemos hacer memoria que, desde su origen, el sistema político fue polémico y provocó una floración de distintas teorías. Si bien es cierto, que en sus primeros años bastó la explicación de que se trataba de un régimen singular, surgido de un movimiento revolucionario, que iba caminando lentamente a la democracia. También se empezó a recalcar el carácter autoritario del régimen, ya que para muchos se trataba de una monarquía sexenal absoluta, o, por lo menos, de una aplicación "desviada" o "deformada" del régimen presidencial, a la mitad del camino entre el autoritarismo y la democracia.

En el año $2000^{11}$ se da por primera vez la alternancia en el país. La oposición logra el triunfo con el Partido Acción Nacional (PAN) ${ }^{12}$, el cual va a repetir su triunfo en las elecciones de 2006. En esa elección, los

11. En las elecciones del 2000 contendieron a la Presidencia de la República, Francisco Labastida por el PRI, Vicente Fox por el PAN, y Cuauhtémoc Cárdenas por el PRD, éste último en su tercera participación por la máxima magistratura, ya que había contendido en 1988 a través de un Frente, elección muy cuestionada; 1994 año álgido por varios acontecimientos políticos y económicos.

12. El Partido Acción Nacional fue fundado el 16 de septiembre de 1939, y se puede ubicar como un partido de centro derecha. En la historia de este partido, se puede afirmar dos momentos claves para posicionarse como la oposición al partido hegemónico PRI. El primero es después de la guerra cristera que se suscita a inicio de los años 30s, ya que muchos de los actores de ese movimiento se van a unir para formar el PAN; y el segundo, es después de las constantes devaluaciones y crisis económicas que sufre el país en las décadas de los 70 s y 80 s, aunado a la nacionalización de la banca, el sector empresarial se va a vincular más con este partido, para participar de manera más activa en la toma de decisiones. dos grandes contendientes Felipe Calderón del PAN y Andrés Manuel López Obrador ${ }^{13}$ del PRD, van a protagonizar una contienda electoral bastante crispada. Cabe resaltar que el proceso electoral no sólo era una contienda para obtener la Presidencia de la República, sino también una confrontación ideológica sobre la visión del Estado. De acuerdo con que el PAN seguía con la visión neoliberal y el PRD con un planteamiento más de corte social y fortalecimiento del Estado. Es menester mencionarlo, ya que, desde los años 80s en México se impuso desde el exterior una visión de la economía globalizada con políticas neoliberales. En ese sentido, tanto el PRI como el PAN compartían la misma perspectiva económica, así que no había un conflicto ideológico, ya que era el mismo sistema económico. Con tal antecedente, la elección de 2012 resultaría otra vez la misma confrontación entre visiones del estado, pero el PAN sería sustituido por el PRI en contra del PRD, resultando como ganador el partido que en su momento fue el hegemónico. Así que, después de dos períodos presidenciales gobernados por el PAN, en el 2012 regresaría el PRI.

Como se había comentado, entre el PRI y el PAN puede existir una diferencia ideológica polítca, pero no económica, lo que provocó que para el inicio de la gestión de Peña Nieto se lograra algo impensable: que se les sumara el PRD para llevar a cabo una serie de modificaciones constitucionales en materia fiscal, laboral, educativa, política, económica pero principalmente en materia energética, la que se va a conocer como el Pacto por México. A estas modificaciones constitucionales, se va a plantar en contra un partido político de reciente creación: MORENA $^{14}$, el cual era encabezado por

13. Andrés Manuel López Obrador surgió de las filas del PRI, pero con la separación de Cuauhtémoc Cárdenas para la elección de 1988, y a la postre para conformar el PRD en 1989. En el 2000 quedó electo como jefe de la Cd. De México, sin embargo, la relación con el presidente Fox, siempre fue muy crispida, y esto se acentuó con el proceso de desafuero, promocionado por este último. En el proceso electoral del 2006 fuer de lo más cerrado, ya que hubo una diferencia de menos .5\% entre Calderón y López Obrador, y siempre con la sombra de un fraude electoral.

14. El partido político Movimiento de Regeneración 
López Obrador , lo que va a ser determinante para la contienda de $2018^{15}$, ya que lo que se pone bajo la lupa o la palestra, eran precisamente los resultados de las reformas constitucionales del Pacto por México. Al no tener los efectos esperados, la ciudadanía se volcó a favorecer al último con su voto para la Presidencia de la República, obteniendo un resultado aplastante frente a los otros 3 partidos tradicionales y los independientes, ya que logra más del $50 \%$ de los votos, algo impensable para muchos.

\section{LA CUARTA TRANSFORMACIÓN Y LA REMASTERIZACIÓN DEL PRESIDENCIALISMO MEXICANO}

El proceso electoral de 2018 confrontaba dos visiones de México, uno representado por los partidos tradicionales PRI, PAN y PRD, quienes defendían las denominadas reformas estructurales mejor conocidas como el Pacto por México. Por el otro lado, los críticos a estas encabezados por MORENA. El resultado de dichas elecciones fue inesperado para todos, ya que este último partido logró una aplastante victoria, obteniendo más del $50 \%$ de los votos y logrando un control en el Congreso de la Unión, y la gran mayoría de los Congresos Locales.

Si bien es cierto, durante los últimos 3 sexenios el presidencialismo mexicano se ha bía atenuado, ya que ninguno de los partidos en el poder había logrado la mayoría en los parlamentos, en el ya mencionado proceso, surge de nuevo un partido político predominante, con amplias mayorías en el Congreso y con una gran base electoral. Los resultados electorales vendrían a provocar

Nacional inicio su ruta a la Presidencia desde el proceso electoral de 2012, ya que su líder Andrés Manuel López Obrador, va a crear esta agrupación de forma paralela al PRD, ya que, en este último partido, empezaron a cuestionar el liderazgo del ya dos veces candidato.

15. Resulta bastante interesante esta elección, ya aquel por primera vez se van a postular los candidatos independientes. Los contendientes de esta elección son los siguientes, por el PRI José Antonio Meade (quien había sido secretario de Estado en los gobiernos del PAN y del PRI), Ricardo Anaya, por el PAN, Margarita Zavala (ex primera dama, esposa del presidente Calderón) Independiente, José Antonio Rodríguez (mejor conocido como el Bronco) también Independiente, y Andrés Manuel López Obrador por Morena. la remasterización del presidencialismo mexicano, en el cual, el titular del ejecutivo asume todas las facultades metaconstitucionales que sus predecesores tenían, en la época del partido hegemónico. Ello resulta de vital importancia ya que, bajo la premisa de Lord Acton, "el poder absoluto, corrompe absolutamente". En ese tenor, en el sistema mexicano, el presidente es titular del Ejecutivo, jefe de Estado, pero, además, de facto jefe del partido político en el poder. Lo que provoca que quienes tengan aspiraciones políticas deban contar con el beneplácito de este.

Debemos resaltar esa situación ya que, con el bono democrático de haber logrado un triunfo con más del $50 \%$ de los votos, obtiene una gran legitimidad. Lo que origina una impregnación en su visión y forma de gobernar, provocando una erosión paulatina de las limitaciones políticas constitucionales que percibimos como existentes. De la misma forma, resurgirían esas facultades metaconstitucionales que se deben más a una realidad política, provocando una nueva pauta de llevar la política. Los frenos y contrapesos a los que estábamos acostumbrados con los últimos presidentes resultan inoperantes frente al nuevo presidencialismo mexicano, ocasionando que ninguna de las instituciones políticas del Estado queden indemnes al impacto del decisionismo y pudiera cobrar las dimensiones que el propio Schmitt planteó en Weimar durante la Época Entre Guerras.

Frente a esa realidad, aunada los problemas que ha provocado la pandemia del COVID-19, resulta imperante analizar el estado constitucional, desde la perspectiva más analítica y de mayor rigor científico que es el que se ubica en el debate constitucional de la época de Weimar. En el momento en que nos encontramos se podrían encontrar soluciones, sin embargo, también algunas tentaciones, lo cual sería bastante peligroso para el Estado Constitucional de Derecho. 


\section{EL DEBATE TEÓRICO DE WEIMAR Y EL PRELUDIO DE LA CRISIS CONSTITUCIONAL ACTUAL}

Tal vez la afirmación con la que titulamos el presente apartado podría resultar bastante fuerte o polémico. Sin embargo, resulta pertinente traer a colación dicho debate, ya que es el más rico y aleccionador que se da en la época Entre Guerras, la cual se conocerá como la Teoría Constitucional de Weimar (RUIPÉREZ, 2010, p. 723.). Desde dicha perspectiva, se puede considerar a Weimar como el símbolo de determinados problemas vinculados con la República de Weimar. No obstante, resulta imprescindible trasladar a la actualidad algunos conceptos, como lo son la teoría democrática del pueblo, las cuestiones jurídicas de la defensa de la Constitución o del "estado de excepción" (LEPSIUS, 2008, p. 45). Por ello, se debe recurrir al debate teórico de la época, para dar una explicación a los problemas actuales. En el momento que se vive son precisamente esos problemas e incluso las mismas soluciones las que se están planteando como solución para enfrentar los grandes temas que ha arrojado el COVID-19. En los que, precisamente, el Estado se está viendo superado en lo elemental: salud, educación, y seguridad.

Asimismo, el análisis de los planteamientos de Weimar es el resultado del conflicto de métodos y orientaciones de la doctrina del derecho público y político, que va a marcar la visión que se tenga de los mismos tópicos casi una centuria después. Porque en ese sentido, el debate sobre determinados problemas constitucionales se puede centrar en la discusión metodológica para solventar las incógnitas políticas y jurídicas. Desde el estudio, o análisis de los derechos fundamentales, la transición de un Estado monárquico con desplazamiento de la república como legitimación de la soberanía popular, y con la imposición de un régimen autoritario. Tales cuestiones, se van a posicionar ante la metodología adoptada por los grandes juristas de la época: Kelsen, Schmitt, Smend y Heller. Así, el debate teórico que se puede trasladar a inicios del siglo XXI.
Los postulados de los autores en cuestión siguen teniendo repercusiones en los debates actuales del derecho constitucional, e incluso siguen tan vigentes que hasta de forma inconsciente se siguen los lineamientos de algunos de estos grandes teóricos. Para Lepsius el tratamiento de los problemas concretos es resultado de los conflictos sobre el método y, a la inversa, resulta necesario para el análisis de los presupuestos y criterios metodológicos para resolver dichos problemas. De ahí la importancia de estudiar a la República de Weimar y sus debates de derecho constitucional, ya que la discusión es lo que se puede considerar como los "tópicos universales", como lo son la idea de supremacía constitucional, la soberanía de la constitución y del pueblo, el debate entre legalidad y legitimidad.

Para el mejor entendimiento, procederemos a establecer algunas líneas introductorias para el entendimiento metodológico de estos autores. Para Carl Schmitt, el Estado es una categoría del ser y se sirve, como ciencia de referencia, de la filosofía política del existencialismo. Para el autor, el estudio del objeto que es el Estado debe ser interdisciplinario, pero con un método no interdisciplinario que es la decisión concreta. En otras palabras, el objeto de estudio que es el Estado se debe abordar desde perspectivas interdisciplinarias, sin embargo, su se debe analizar de una manera concreta (SCHMITT, 2001, p. 78).

Kelsen tiene un ideal del objeto referida al ser, pero orientada al Derecho, analizando de manera concreta, solamente desde la perspectiva científico-jurídica. Por lo cual, no se puede acceder a ello por métodos interdisciplinarios, sino solamente jurídicos. Para el autor austriaco, la referencia de la norma al hecho, del deber ser al ser, se encuentra implícita en el concepto de positividad (KELSEN, 1979, p.327). Ya sea que la realidad siga a la norma (validez del Derecho constitucional), o que la norma siga a la realidad (reforma constitucional). Para Kelsen una Constitución es el fundamento de las normas jurídicas siempre cambiantes, que necesariamente se modifican. Kelsen establece como el fundamento de validez 
de una norma sólo puede encontrarse en la validez de otra. La norma que representa la base de validez de otra es caracterizada, metafóricamente, como una norma superior en relación con una inferior (KELSEN, 2005, p. 201), ello constituye el fundamento de validez de todas las normas, inclusive de los ordenamientos inferiores.

Dicha norma recibe el nombre de Constitución y ésta representa, con relación a la Ley, un grado superior del orden jurídico. La Constitución es aplicada por la ley en el sentido que el procedimiento legislativo se encuentra determinado en los preceptos constitucionales, del mismo modo que la ley determina la sentencia que la aplica. Lo que Kelsen afirma es que la norma superior es la que da origen a la norma inferior. Sin embargo, ésta a la vez es la ejecución de la norma superior. Para el autor austriaco y principal defensor del positivismo, el método científico-jurídico es el que se debe utilizar para estudiar el derecho, y eliminar cualquier otro método para su análisis.

Smend considera que el Estado se encuentra enmarcado dentro de una realidad dinámica, con factores siempre cambiantes, y ordenamientos en constante flujo. El Estado es real en la medida en que se actualiza o se reproduce continuamente. El autor denomina la integración al proceso cambiante, que es el núcleo sustancial de la dinámica del Estado, en virtud, de que existe únicamente a causa de y en la medida en que se encuentra en proceso de autointegración (SMEND, 1984, p. 159).

Como consecuencia, el Estado no limita su vida sólo a aquellos momentos de la realidad contemplados por la Constitución. Para tener una vigencia efectiva en la vida política, la Norma Fundamental ha de tener en cuenta toda la enorme gama de impulsos y de motivaciones sociales de la dinámica, integrándose progresivamente. Por su propia naturaleza, la Carta Magna no tiende a regular supuestos concretos, sino de abarcar la totalidad del Estado y del proceso integrador. Smend admite en cuanto al método y objeto, una especial apertura de interpretaciones, el objeto de conocimiento puede ser tan fáctico como normativo, y el método para acceder a él puede seguir un procedimiento extrajurídico interdisciplinario. Lo que denominó como "las ciencias del espíritu", en el caso de ser orientado hacia el Estado o ser normativizado cuando se articula la tarea integradora del Derecho.

Por último, Heller orienta al Estado como objeto interdisciplinario, parecido al de Schmitt. Sin embargo, su método de análisis también va a ser interdisciplinario describiéndolo como la "ciencia de la realidad", o como se refiere Ruipérez, al estudio de las ciencias constitucionales (RUIPÉREZ, 2010, p. 765). Para Heller, el derecho constitucional es el lugar donde confluye lo jurídico con lo político, y resulta imperativo encontrar un equilibrio entre ambos. La Constitución no puede ser analizada solamente desde unos de sus elementos, el jurídico o político, ya que se eliminaría uno de sus componentes. Por tal motivo, su método debe ser el de las ciencias constitucionales, donde debes tomar todos los elementos que confluyen en la sociedad, desde lo político, jurídico, sociológico, económico, e inclusive hasta lo histórico, para poder dar soluciones a los problemas constitucionales.

Es Hermann Heller quien establece que no pueden analizarse por separado lo dinámico y lo estático, ni la normatividad y la normalidad, el ser y el deber ser. La normatividad y la existencia (normalidad) no son para el Estado cosas opuestas, sino condiciones recíprocas. La normatividad no se establece por sí sola, debido a que para su efectividad se requiere que exista necesidad de esta. De acuerdo con el autor, las normas jurídicas exigen una normatividad consciente, se busca el deber ser, porque la normalidad requiere ser reforzada por la normatividad (HELLER, 1995, p. 89).

Para Heller, la Constitución normada no consiste en preceptos jurídicos autorizados por el Estado, sino que, para su validez, precisa siempre ser completada por elementos extrajurídicos, como la aceptación por parte de aquellos a quienes la norma se dirige y la observan. El autor asienta que 
los preceptos pueden sufrir una evolución gradual y, no obstante, permanecer inmutable el texto del precepto constitucional, a pesar de que se sentido experimenta una completa revolución.

\section{NORMALIDAD VS NORMATIVIDAD Y LA TENSIÓN ACTUAL}

Una vez analizados los grandes teóricos, donde sus discusiones después de un siglo siguen teniendo eco en las cuestiones constitucionales actuales, es necesario resaltar como los problemas de la época de Weimar no son exactamente iguales, no obstante, no por eso debemos omitir su estudio o su análisis. En Weimar, el principal problema se devenía de la crisis política y económica en la que se encontraba Alemania después de la Primera Guerra Mundial y, con una constitución que transitaba de una monarquía a una república, que provocaba bastantes detractores por sostener el status quo. Hay que recordar que la Constitución de Weimar, era, al igual que nuestro texto mexicano de 1917, uno de los primeros ordenamientos de corte social, y con programas muy ambiciosos en esa parte de derechos fundamentales. La crisis económica en la que se vio envuelto Alemania después de la Gran Guerra y provocada por las sanciones que les fueron impuestas, llevaran a ese pueblo teutón a buscar soluciones a estos problemas; y es precisamente aquí la valía de estos autores, ya que algunos de los problemas que vivieron, están saliendo relucir con la Pandemia y el contexto actual.

No obstante, nuestra situación es más compleja de la que se vivía en Weimar, ya que hoy en día, además de la situación económica, tenemos una cuestión de salud, la cual, aqueja a todos. Como lo hemos señalado, el conflicto en Weimar repercutió principalmente en Europa, lo alarmante ahora, es que nuestra crisis es un fenómeno mundial con distintos frentes, ya que no es solamente el económico, y de seguridad, sino que debemos sumarle las cuestiones de salud, educación, y política, y en este sentido, el mismo estado constitucional.
Si bien es cierto, las teorías de estos grandes teóricos fueron desarrolladas en los años 20s del siglo pasado, y para algunos quedaron concluidas con el final de la República de Weimar ${ }^{16}$, no dejan de estar vigentes, tal y como lo señalaremos en las siguientes líneas. La situación de emergencia provocada por la pandemia ha puesto a todos los sistemas democráticos en crisis para enfrentarla. Prácticamente en todas las latitudes no se ha logrado una respuesta correcta a este problema. Es por eso, que se han escuchado distintas voces que pretenden replantear el esquema de la democracia constitucional. Como lo habíamos comentado anteriormente, la crisis que se desata en Weimar, se podría decir que inicia localmente, pero sus repercusiones se van a extender en todo el mundo. Ahora con el COVID-19, de forma inmediata trastoca a todo el orbe, y es precisamente por ello que la democracia, los derechos fundamentales $y$ el equilibrio de poder pueden sufrir vulneraciones.

El texto constitucional de Weimar en su artículo 48 establecía como mecanismo para hacer frente a las situaciones de crisis el Estado de excepción. Va a ser el propio Schmitt, quien, con fundamento en ese precepto constitucional, desarrolle gran parte de su teoría. Para el autor, es soberano quien decide el estado de excepción (SCHMITT, 2001, p. 23). Y prosigue, si los estados individuales ya no cuentan con la facultad autónoma de declarar el estado de excepción o decretos de emergencia, de acuerdo con el artículo 48 de dicho ordenamiento, dejarían de ser estado. Schmitt afirma que la excepción es más interesante que el caso de

16. Los autores que hemos estado analizando, no van a intervenir en las discusiones que se llevaron a cabo en la República Federal Alemana. Carl Schmitt fue despojado de su cátedra después de 1945, y tampoco fue admitido como miembro de la refundada Asociación de Profesores Alemanes de Derecho Político. Hans Kelsen emigro de los Estados Unidos a la Universidad de Beckley California, donde moriría en 1973. Rudolf Smend se retiró en Göttingen, y se dedicó más el estudio del derecho eclesiástico, y solamente tuvo una participación relevante en los festejos conmemorativos del décimo aniversario del Tribunal Constitucional Federal. Y Hermann Heller, emigra a España en marzo de 1933 para incorporarse como profesor de la Universidad Central, hoy Universidad Complutense de Madrid, donde fallece ese mismo año, dictando una de sus clases. 
normalidad, para él, lo normal no demuestra nada, es la excepción lo que demuestra todo. En la excepción, la fuerza de verdadera vida rompe la costra de un mecanismo cuajado en la repetición.

Por lo manifestado, frente a las crisis actuales una de las salidas o posible solución pudieran ser decretar los estados de emergencia, situación que se vive en distintas partes, ya sea conforme a derecho o lo más peligroso que se realicen de facto. Bajo la tensión provocada por la confusión del poder constituyente, de acuerdo con Schmitt, es planteamiento de un poder constituyente prolongado y soberano sin límites. Es lo que va a plantear la idea de la defensa de la Constitución, quien, basándose a las premisas planteadas por Constant con su poder moderador, va a justificar la idea del Reich como el garante de la Constitución.

Por tal motivo, resulta imperante recordar que el gran problema del derecho constitucional es que el poder constituyente pretenda realizar funciones de poderes constituidos, o lo que es más alarmante, que los constituidos pretendan usurpar las funciones del constituyente. En este tenor de ideas, la tentación que se puede suscitar bajo la presente crisis es la cuestión de esos políticos prácticos, a los cuáles no les está vetado nada, de suerte que, incluso en el marco de un régimen democrático, pueden llegar a discutir o negar el principio de legitimidad sobre el que se construyó el sistema constitucional en el que operan.

Si bien es cierto, bajo la problemática de poder constituyente y poderes constituidos, la crítica que se le otorga a Schmitt se realiza desde el protagonismo de los poderes ejecutivos. Bajo ese mismo argumento, se puede plantear al propio Kelsen en la idea de justificación del positivismo jurídico, que también puede recaer en un positivismo jurisprudencial.

Lo que han pretendido los defensores de un positivismo jurídico efervescente, quienes apelan a la idea kelseniana de que una "norma vale como norma de Derecho únicamente porque nació de una cierta manera, porque fue creada según una regla determinada, porque fue producida con arreglo a un método específico". Se ha llegado incluso afirmar que la transformación del orden constitucional estatal puede llevarse a cabo sin necesidad de poner en marcha el proceso de reforma constitucional establecido, ya que bastaría, por el contrario, la entrada en vigor de una norma jurídica ordinaria que haya sido aprobada válidamente desde el punto de vista formal.

Ya Kelsen afirmaba que no existe inconstitucionalidad material, lo único que hay es la inconstitucionalidad formal, porque las leyes no resultan inconstitucionales por contrariar los contenidos materiales de la Constitución, sino por ser aprobadas pro el Poder Legislativo y a través de un procedimiento que no encuentra facultado para derogar a la Norma Fundamental. La ley ordinaria no sería declarada inconstitucional, si hubiera sido aprobada a través del procedimiento de la reforma constitucional (KELSEN, 1979, p. 403).

Por todo lo anterior, consideramos que la visión de Heller resulta la más adecuada para encontrar respuestas a los problemas actuales. Desde los planteamientos que hace el autor en su obra "Europa y el fascismo" (2006, p.137), como la obra que mejor puntualiza la atracción que ejercían en los totalitarismos ascendentes las construcciones acríticas y a valorativas del positivismo jurídico formalista, que, partiendo de la ingenua idea kelseniana el Estado de Derecho, era posible con independencia del contenido ético, político y social de que se le dote.

Como se había comentado anteriormente, Heller afirma que la doctrina de la división de poderes de Montesquieu no es sino un procedimiento técnico para transformar la voluntad general, portadora y creadora de los valores, en una ley cuya imperatividad no admita perturbaciones (HELLER, 1983, p. 87). En la importancia de esta separación de poderes se encuentra la respuesta del constitucionalismo moderno contra el peligro recurrente del despotismo. 
Para Heller, sólo en el Estado de Derecho, con división de poderes, existe una conexión entre legalidad y legitimidad, y esa conexión es tanto material como formal y de técnica de organización. Para llevar a cabo esa separación se precisa, como base, un criterio jurídico que hay que admitir que está por encima del Estado y de su derecho positivo. Al derecho, como valor supra-positivo de distribución y medida, le incumbe la función de ordenar rectamente la vida social. Es decir, atribuir a todos sus miembros lo que, con referencia a un todo, les corresponde en facultades y obligaciones, establecer entre ellos una justa relación o equilibrio de poder.

Para el autor, la teoría del Estado investiga la realidad de la vida estatal. Aspira a comprender al Estado en su estructura y función actual, su devenir histórico y las tendencias de su evolución. La ciencia política sólo puede tener función como ciencia, si se admite que es capaz de ofrecer una descripción, interpretación y crítica de los fenómenos políticos (HELLER, 1983 p. 19). Para Heller, la realidad histórica es el punto de partida de la Teoría del Estado como ciencia de estructuras. Por tal motivo, no se puede olvidar que, en ningún momento, el Estado es algo que deviene. Pero tampoco se puede desconocer que el Estado da forma a este devenir político. En ese sentido, la Teoría del Estado, en cuanto ciencia de la realidad, ha de mostrarnos el "si" y el "cómo" existe el Estado, en cuanto unidad concreta que actúa en el tiempo y en el espacio.

Heller realiza una aguda crítica a los postulados de Kelsen, al señalar que al contraponer el deber ser, el carácter jurídico, al ser, de carácter social, sin que entre ellos exista una relación, considerando al primero como un deber ser independiente de toda orden y de toda observancia, atiende única y unilateralmente a la normatividad y olvida que todo el deber social se relaciona constantemente con un querer humano. Para Heller, las normas sociales no son afirmaciones teóricas, sino exigencias dirigidas a la voluntad del hombre. El ser y deber ser son elementos antagónicos que no pueden ser referidos sin el uno y el otro, ni ambos a una común raíz lógica, pero sí pueden ser enlazados en el concepto de la ordenación normativa social. Pues, un deber social que, por principio, no guardase relación alguna con un ser social al que hubiera que dar forma, no sería en puridad, un deber ser. Para Kelsen toda norma jurídica vigente en el Estado es una norma de Derecho Positivo, en la que el único requisito es que esta fuese aprobada a través del procedimiento $\mathrm{y}$ formas adecuadas previamente establecidos. Para Heller, por el contrario, es necesario que además la norma jurídica aprobada reúna otras condiciones que, en este caso, son de carácter político y material.

Heller es consciente que existen actores como el jurista dogmático, o como el "jurista judicial" que cometen el error de considerar los cuerpos normativos y la jurisprudencia como normas ideales, independientes de toda actividad volitiva y facticidad. El jurista judicial puede, fácilmente, pasar por alto el hecho de que el precepto jurídico concreto sólo tiene validez gracias a su inclusión en la conexión sistemática de una jerarquía de poder y del orden jurídico a ella correspondiente. Para Heller, sin el carácter de creador de poder que el derecho entraña no existe ni validez jurídica normativa ni poder estatal, pero sin el carácter de creador de derecho que tiene el poder del Estado no existe positividad jurídica ni Estado. Por tal motivo, la autoridad de la voluntad del Estado, su cualidad de poder supremo se basa en su legitimidad.

Heller afirma, que, si la unidad del estado sólo nos fuera dada realmente por la ciencia jurídica, en el sentido que lo hace Kelsen, sería evidentemente inconcebible como realidad. La unión normativa interindividual que se da en el orden jurídico entre voluntades individuales, que en la realidad están disociadas, no basta para explicar la existencia del Estado. De la unificación volitiva nace en el cómo un proceso de ordenación y acomodación dentro de cada individuo, que se ve presionado en cada momento por la conveniencia social $\mathrm{y}$ en quien la educación de numerosas generaciones engendra el estado habitual de una conciencia de los individuos. 
Para Heller la democracia es una estructura de poder construida de abajo hacia arriba, en la que rige el principio de soberanía del pueblo: todo poder estatal procede del pueblo. No obstante, hace la aclaración que, si bien es cierto, en la democracia existe una igualdad de oportunidades, el pueblo sólo puede mandar a través de una organización de dominación. Para el autor, el requerir la intervención directa del Cuerpo Electoral para la aprobación de todas las leyes, puede presentar determinados problemas en el funcionamiento ordinario del moderno Estado Constitucional. El pueblo, como portador del orden estatal, determina en todas partes la voluntad del estado. Sin embargo, la unificación de las voluntades no se transforma automáticamente en la voluntad del orden estatal, siendo necesario al efecto, la individualización última de la voluntad por las instancias del Estado. Dichos organismos representativos encarnan en sí mismos, los valores y fuerzas de la comunidad, mismos que son, a su vez, los elementos determinantes de la unidad volitiva (HELLER, 1995, p. 178).

Resulta indispensable resaltar, que Heller al momento en que trabaja con las normas jurídicas, así como la realidad, no se ciega a la idea que un Parlamento represente a todo el Cuerpo Político. Es consciente que desde el realismo político que ninguno de los gobernantes antidemócratas que han existido a lo largo del periodo el constitucionalismo, han renunciado a conformar formalmente un Parlamento. Por tal motivo, para Heller la representación ya sea en el sistema parlamentario o en otro, debe concebirse como institución subordinada al pueblo. De esa manera, queda excluida cualquier forma de soberanía de los órganos estatales y, al mismo tiempo, quedan identificadas la soberanía del pueblo y la soberanía del Estado.

Ruipérez (2014, p. 252) resalta que en el marco de las concepciones del Derecho Constitucional de Hermann Heller es donde el Instituto de la Reforma Constitucional aparece en toda su magnitud, no sólo como mecanismo que garantiza la continuidad y vigencia de la Constitución. Lo cual puede entenderse en la medida en que la Verfassungsänderung que se utiliza para que voluntad del Poder Constituyente, se adecue a las nuevas realidades políticas, sociales y económicas, sosteniendo los mismos principios y valores que determinaron la aprobación de esa Constitución. Es lo que define como el quid de asegurar el mantenimiento de la realidad constitucional. La Constitución permanece a través del cambio de tiempos y personas gracias a la probabilidad de que se repita en el futuro la conducta humana que concuerda con ella.

Es a través de la reforma constitucional como mecanismo de articulación que se puede lograr la continuidad jurídica del Estado, en este sentido, queda fácilmente identificado que, en la teoría de Heller, podemos encontrar la existencia de límites materiales a la reforma constitucional. Para ese autor, la Constitución es la que incorpora y consagra los principios y valores del Cuerpo Político, o al menos los de la mayoría de los ciudadanos del Estado. Asimismo, sólo goza de una auténtica vigencia, $y$, en consecuencia, únicamente adquiere la condición de norma jurídica obligatoria y vinculante para gobernantes y gobernados cuando permanece la voluntad Poder Constituyente. Sólo puede crearse una continuidad constitucional y estatus político, si el legislador que actúa en el proceso de reforma se considera ligado por ciertas decisiones, normativamente objetivas, de sus predecesores. Sólo mediante el elemento normativo se normaliza una situación de dominación actual, por eso para Heller, una Constitución dura más allá del momento presente.

Por lo anterior, Heller es quien mejor concibe a la Verfassungsänderung como poder limitado, aunque jamás lo diga de forma expresa. No obstante, para el alemán la reforma constitucional es un procedimiento que es puesto en marcha por las fuerzas políticas, actuando como poderes constituidos extraordinarios, materializar el cambio, pero un cambio que es obligadamente limitado y no, bajo ningún concepto, el llevar a cabo actos revolucionarios. 
Heller, realiza postulados a partir de la Libertad y Democracia. En el entendido que estas no se logran sólo con un conjunto normativo, que para esto no podemos dejar de analizar el elemento político. La diferencia sustancial, entre actos revolucionarios y golpes de estado, son precisamente quienes llevan a cabo estos movimientos. Si quien los perpetra lleva implícitos los ideales de la democracia, justicia, y libertad son actos revolucionarios y, por el contrario, serán golpes autoritarios con la pretensión de establecer regímenes totalitarios los que desconocen estos ideales. De las teorías o planteamientos que se hicieron en la época Entre Guerras, consideramos que la más acertada y adecuada para enfrentar la crisis es precisamente la realizada por Heller, ya que es quien metodológicamente considera todos los elementos para dar soluciones, además que lo hace partiendo de los ideales de la democracia y libertad.

\section{CONSIDERACIONES FINALES}

La realidad que teníamos ha cambiado de una forma tan acelerada que vamos a tardar en acostumbrarnos a la nueva normalidad. La erupción de la pandemia del COVID-19, ha provocado que todas nuestras ideas o formas de llevar a cabo las cosas se replanteen, y nuestras instituciones jurídicas, políticas, económicas y sociales no serán la excepción. Hemos visto cómo en distintas latitudes se han enfrentado a la situación, y se han escuchado distintas voces o análisis de que en cierta medida los países con regímenes más autoritarios han logrado mejores resultados, frente a los obtenidos por los estados democráticos en el combate a esta enfermedad, que ha azotado a todo el mundo.

La democracia se encuentra en momento de inflexión, ya que podemos ubicar en cierta medida, las crisis constitucionales en las que estamos, a la que se suscitó en Weimar en la época entre guerras. Las tensiones se asemejan, y de acuerdo con los distintos planteamientos teóricos podemos encontrar soluciones o inclusive retroceder en las conquistas ya logradas, y estas respuestas pueden estar en un positivismo de Kelsen, decisionismo de Schmitt, integracionismo de Smend, o el análisis de metodológico de las ciencias constitucionales de Heller. El tratamiento de los problemas concretos es resultado de los conflictos sobre el método y, a la inversa, resulta necesario para el análisis de los presupuestos y de los criterios metodológicos para resolver dichos problemas. Y de ahí la importancia de estudiar a la República de Weimar y sus debates de derecho constitucional. Ya que la discusión es lo que se puede considerar como los "tópicos universales", como lo son la idea de supremacía constitucional y la soberanía de la constitución y del pueblo, el debate entre legalidad y legitimidad.

El presidente mexicano tenía múltiples facultades, que provenían de distintas fuentes, como son la Constitución, las leyes ordinarias y el sistema político. De las anteriores fuentes, hay que entender que el primer mandatario del país obtuvo la gran fuerza o poder de la última de ellas, en otras palabras, del sistema político mexicano, a lo se ha denominado las "facultades metaconstitucionales". Los frenos y contrapesos a los que estábamos acostumbrados con los últimos presidentes resultan inoperantes frente al nuevo presidencialismo mexicano, y esto se ha hecho sentir, lo que ha provocado que ninguna de las instituciones políticas del Estado quede indemnes al impacto de este decisionismo.

Frente a esa realidad, aunada a los problemas que ha provocado la pandemia del COVID-19, resulta imperante analizar el estado constitucional, desde la perspectiva más analítica y de mayor rigor científico que es el que se ubica en el debate constitucional de la época de Weimar. Ya que en el momento en que nos encontramos, en dicha discusión se podrían encontrar soluciones. Sin embargo, también algunas tentaciones, lo cual sería bastante peligroso, para el estado constitucional de derecho. 


\section{REFERENCIAS BIBLIOGRÁFICAS}

„ AA.VV. (2010). Teoría de la Constitución, Estudios en Homenaje al Dr. Jorge Carpizo en Madrid. México: Porrúa.

» ARENDT, H. (2017). Los Orígenes del Totalitarismo. Madrid: Alianza Editorial.

» BOBBIO, N., (1992). El Futuro de la Democracia. México: FCE.

» BURKE, E. (1996). Textos Políticos. México: FCE.

$»$ CARPIZO, J. (2009). Concepto de Democracia y Sistema de Gobierno en América Latina. México: UNAM.

» CARPIZO, J. (2004). El Presidencialismo Mexicano. (18ª ed.). México: Siglo XXI.

» CARPIZO, J. (2004). La Constitución Mexicana de 1917. (14a ed.). México: Porrúa.

» CARRÉ DE MALBERG, R. (1988). Teoría General del Estado. (2ª ed.). México: FCE.

» COnstant, B. (1989). Escritos Políticos. Madrid: Centro de Estudios Constitucionales.

» DAHL, R. (1989). Democracy and its Critics. E.U.A.: Yale.

» DI TELLA, T. (1988). Crisis de la representatividad y sistema de Partidos Políticos. Argentina: Grupo Editorial Latinoamérica.

» DUVERGER, M. (1970). Instituciones Políticas y Derecho Constitucional. (5 ${ }^{\mathrm{a}}$ ed.). España: Ariel.

» FERNÁNDEZ-MIRANDA CAMPOAMOR, C. y FERNÁNDEZ-MIRANDA CAMPOAMOR, A. (2003). Sistema electoral, Partidos Políticos y Parlamento. Madrid: Colex.

» GUASTINI, R. (2000). Rigidez Constitucional y límites a la Reforma en el Ordenamiento Italiano. Jurídica, Anuario del Departamento de Derecho Universidad Iberoamericana, (30), 175 - 194.

» HAMILTON, MADISON y JAY. (1974). The Federalist. E.U.A.: The University of Texas.

» HELLER, H. (1983). Teoría del Estado. México: FCE.

» HELLER, H. (1995). La Soberanía. (2ª ed.). México: FCE.

» HELLER, H. (2006). Europa y Fascismo. Granada: Comares.

» JELLINEK, G. (2000). Teoría General del Estado. México: FCE.

» KELSEN, H. (1979). Teoría General del Estado. México: Editora Nacional.

» KELSEN, H. (1999). ¿Quién es el Defensor de la Constitución? (2ª ed.). Madrid: Tecnos.

$»$ KELSEN, H.(2002). Esencia y Valor de la Democracia. (2ª ed.). México: Colofón.

» KELSEN, H. (2005). Teoría Pura del Derecho. (14aa ed.). México: Porrúa

» LEPSIUS, O. (2008). El Redescubrimiento de Weimar por parte de la doctrina del derecho Público de la República Federal. Revista Historia Constitucional, (9), $259-295$. 
LOEWENSTEIN, K. (1986). Teoría de la Constitución. Barcelona: Ariel.

» MICHELS, R. (2003). Los Partidos Políticos. (Vol. II). Argentina: Amarrortu Editores.

» MONTESQUIEU. (2000). Del Espíritu de las Leyes. (5a ed.). Madrid. Tecnos.

» NOHLEN, D. (2009). La Democracia Instituciones, Conceptos y Contexto. Colombia: Pontificia Universidad Javeriana.

» PECES BARBA, G. (1993). Derecho y Derechos Fundamentales. Madrid: CEC.

» PECES BARBA, G. (2004). Lecciones de Derechos Fundamentales. España: Dykinson.

» PÉREZ LUÑO, A.E. (2001). Derechos Humanos y Estado de derecho y Constitución. Madrid: Tecnos.

» PLATÓN. (2006). La República. Madrid: CEPC.

» PITKIN, H. (1986). El Concepto de Representación. Madrid: Centro de Estudios Constitucionales.

» RUIPÉREZ, J. (2005). "Estudio Preliminar", en La Reforma Constitucional, la organización territorial del Estado, la Unión Europea y la igualdad de Género. Madrid: Biblioteca Nueva.

» RUIPÉREZ, J. (2014). Reforma versus Revolución, Consideraciones desde la Teoría del Estado y de la Constitución sobre los límites materiales a la revisión constitucional. México: Porrúa.

» SCHMITT, C. (1982). Teoría de la Constitución. Madrid: Alianza Editorial.

$»$ SCHMITT, C. (2001). Teólogo de la Política. México: FCE.

» SMEND, R. (1984). Constitución y Derecho Constitucional. Madrid: CEC.

» STUART MILL, J. (2007). Del Gobierno Representativo. (4⿳亠丷a ed.). Madrid: Tecnos.

» TARNAWSKI GESLOWSKA, E. (1994). El Tiempo en las Democracias Inciertas. Revista de Estudios Políticos, (86), 153 - 193.

» VEGA GARCÍA, P. de. (2000). La Reforma Constitucional y la Problemática del Poder Constituyente. ( $5^{\mathrm{a}}$ ed.). Madrid: Tecnos.

» VEGA GARCÍA, P. de. (2003). La Democracia como proceso. (Consideraciones en torno al republicanismo de Maquiavelo). Revista de Estudios Políticos, (120).

» VEGA GARCíA, P. de. (1985). Significado Constitucional de la Representación Política". Revista de Estudios Políticos, (44), 7 - 43.

» VERGOTTINI, G. de. (2004). Derecho Constitucional Comparado. México: UNAM.

» WONG MERAZ, V. A. (2010). Constitución Mexicana, Reforma y Mutación. México: Porrúa.

» WONG MERAZ, V. A. (2010). (2014). La Reforma Constitucional como defensa de la Constitución de 1917. Un análisis desde la problemática del Poder Constituyente y las ideas de Libertad y Democracia. Anuario da Facultade de Dereito da Universidade da Coruña, (18), 195 - 226. 